\title{
Social Change and New Challenges for the Health Care System \\ Introduction to Social Change Review Special Issue
}

\author{
Adela Elena Popa ${ }^{1}$, Dragoş Dragoman ${ }^{2}{ }^{*}$ \\ ${ }^{1}$ Lucian Blaga University of Sibiu, Sociology and Social Work Unit, 2-4 Lucian Blaga, 550169 Sibiu, Romania \\ ${ }^{2}$ Lucian Blaga University of Sibiu, Political Science Unit, 34 Calea Dumbrăvii, 550324 Sibiu, Romania
}

Health problems are placed at the intersection of individual, community and society. Everything affecting society or community has implications on health issues and problems, not only at individual level, but also at society level. Social change in its diverse forms, touching various layers and fields of the social life can have a significant impact on communities and societies and implicitly on health issues. Revolutions, processes of transition, new trends of consumption, fashions, social or economic crises, all these have not only social consequences, but implications on the health of individuals and societies as well. We will further invoke several examples, not necessarily related to the articles in this issue, but pointing to very recent and intriguing social transformations that have influence on health.

The labour market is a field marked by constant transformation: changes in the labour market (unemployment, ageing labour force), changes in the structure and type of work (less physical work, stress and burnout at the workplace, new workplace arrangements, temporary job contracts) and also changes in social security systems. All these can bring about new occupational diseases, new concerns for the occupational physicians and new needs for adjustments at the work place for elderly or diseased people working. As a consequence, new subfields of research have developed recently, at the intersection between health and work, in an effort to find the proper response to the above mentioned changes.

\footnotetext{
* Contact addresses: adela.popa@ulbsibiu.ro (A.E. Popa); dragos.dragoman@ulbsibiu.ro (D. Dragoman)
} 
Migration as a change process involves not only social, economic and political features, but issues related to health. The migrants' health is usually a concern for the host countries, creating the need for proper policies and services and generating pressure on the health care systems of these countries. Migration also implies that along with people, health behaviours, practices and beliefs circulate as well, impacting the origin communities and the destination ones. As a response to these new trends, the relation between migration and health is increasingly studied today. One of the articles in the current issue explores this relation by adding the age element in this equation.

Health care systems are also very dependent on the changes and transformations in political ideologies, governance type or the welfare states. The decentralization processes, bringing health services closer to the users, encouraging involvement of people in communities in decision and implementation of health programmes and allowing for a better (at least in theory) management of resources at local level, are just some examples of how change at large scale can influence health status of people, but also health processes and services.

A last example regards the health education, a critical problem not only for Romania but for many other countries, and more and more a necessity today. Concerns regarding the health education existed long ago. They usually resulted in significant change regarding the approach and treatment of certain diseases. Health education needs also initiated relevant policies for improving the health status and wellbeing of people. Recent similar actions are the social movements of raising awareness in problems such as occupational safety, food safety or the social movements related to the environment health. All these started by acknowledging the health risks in various activities.

The articles in the current issue explore theoretically or empirically very eclectic topics related to health, disease or the health care system. The first one is a theoretical paper, presenting a new and fascinating phenomenon, the pharmaceuticalisation of society. Two of them, drawing 
on quantitative data, target two geographically distinct areas, Greece and Mexico, presenting two significant health issues these two countries are dealing with in the present. We will present briefly the papers below.

The first article of the issue pertains to an increasingly researched phenomenon, which is medicalisation of society. More specifically, it pays attention to pharmaceuticalisation. Its mechanism, as unravelled by the author, is twofold. On the one hand, it consists in the use of drugs or medication to improve individual performance, without consulting a doctor, due to the increasing citizen expertise about the diseases of society. On the other hand, pharmaceuticalisation has brought in recently new actors, with physicians and patients at the centre of the system, but with pharmaceutical industry and the manufacturers of biotechnology, the media and the state as equally significant actors. From this perspective, the growing importance of the pharmaceutical industry in medicalisation is to be taken into account, especially when it comes to point out the new tendencies of shifting from medicalisation towards biomedicalisation, as a process of optimizing health in the future. Pharmaceuticalisation is therefore inevitable in the development of the new interaction patterns between the pharmaceutical firms, doctors, the public, governments and insurance companies. Over the last decades, the society has been increasingly marked by development and innovation in the pharmaceutical field, state de-regulation policies, marketing of drugs and consumerism, with an expansion of world markets and post-modern new perspectives on health.

The second article explores the issue of limited access to basic health services, medical examinations, hospital and pharmaceutical care in times of harsh economic crisis, as it was the case in Greece beginning with 2010. Due to the failure of state capacity to offer access to healthcare, more people have been severely marginalized. This is not only the case of migrants, as usual, but also unemployed persons, people with disabilities and especially senior citizens. The article does not only examine the range of newly excluded groups, but underlines the mechanisms put in place by the local civil society in order to cope with state failure. Local organizations find new groups of 
vulnerable people unmapped by the state and work for the empowerment of local populations. By combining macro-level perspectives from quantitative data, informed opinions of key stakeholders and more micro-perspectives about the real-life impact of the crisis, the author points out toward the synergies between stakeholders and civil society initiatives, aiming to provide the local population not only with health services, but also with a wider range of social care services (dormitory for homeless people, food distribution, elderly care program, etc.). The conclusion of the article sheds light on the capacity of the community to overcome social catastrophes and on the willingness of the voluntary sector (among whom the Orthodox Greek Church is the most important) to supply the state wherever and whenever it fails.

The third article investigates how the violence and abuse against elderly migrants in Monterrey, Mexico affects their health. The problem is more and more acute due to economic migration from rural country-side to urban areas in search for a better life, but also due to fast ageing that transforms modern societies. The types of discrimination and violence suffered by elderly migrants at their work place, as well as at home, may be caused by caregivers or employers or by any other. Those types range from physical, psychological, sexual, financial to neglect. Victims of violence have higher rates of depression, anxiety and post-traumatic stress disorder, and worse overall health. This is even more acute in the case of elderly migrants who enter in the informal sector and work as street vendors, domestic help and gardeners, taxi drivers or in construction sites. It is therefore evident why most of elderly migrants suffer many kinds of diseases, including high and low risk. As indicated in the article, ageing and health, violence and abuse have greater impact on the health status of the older migrating population. 